\title{
Quantitative fluorescence using 5-aminolevulinic acid-induced protoporphyrin IX biomarker as a surgical adjunct in low-grade glioma surgery
}

\author{
Pablo A. Valdés, MD, PhD, ${ }^{1-4}$ Valerie Jacobs, MD, PhD, ${ }^{2,5}$ Brent T. Harris, MD, PhD, ${ }^{6}$ \\ Brian C. Wilson, PhD, ${ }^{7}$ Frederic Leblond, PhD, ${ }^{8}$ Keith D. Paulsen, PhD, ${ }^{4}$ and \\ David W. Roberts, MD2,3
}

${ }^{1}$ Department of Neurosurgery, Brigham and Women's/Boston Children's Hospitals, Harvard Medical School; ${ }^{5}$ Department of Neurology, Boston Children's Hospital, Boston, Massachusetts; ${ }^{2}$ Geisel School of Medicine at Dartmouth, Hanover; ${ }^{3}$ Section of Neurosurgery, Dartmouth-Hitchcock Medical Center, Lebanon; ${ }^{4}$ Thayer School of Engineering, Hanover, New Hampshire; ${ }^{6}$ Georgetown University Medical Center, Washington, DC; 7 Ontario Cancer Institute, University of Toronto, Ontario; and ${ }^{8}$ Department of Engineering Physics, Polytechnique Montreal, Quebec, Canada

OBJECT Previous studies in high-grade gliomas (HGGs) have indicated that protoporphyrin IX (PpIX) accumulates in higher concentrations in tumor tissue, and, when used to guide surgery, it has enabled improved resection leading to increased progression-free survival. Despite the benefits of complete resection and the advances in fluorescence-guided surgery, few studies have investigated the use of PpIX in low-grade gliomas (LGGs). Here, the authors describe their initial experience with 5-aminolevulinic acid (ALA)-induced PpIX fluorescence in a series of patients with LGG.

METHODS Twelve patients with presumed LGGs underwent resection of their tumors after receiving $20 \mathrm{mg} / \mathrm{kg}$ of ALA approximately 3 hours prior to surgery under an institutional review board-approved protocol. Intraoperative assessments of the resulting PpIX emissions using both qualitative, visible fluorescence and quantitative measurements of PpIX concentration were obtained from tissue locations that were subsequently biopsied and evaluated histopathologically. Mixed models for random effects and receiver operating characteristic curve analysis for diagnostic performance were performed on the fluorescence data relative to the gold-standard histopathology.

RESULTS Five of the 12 LGGs (1 ganglioglioma, 1 oligoastrocytoma, 1 pleomorphic xanthoastrocytoma, 1 oligodendroglioma, and 1 ependymoma) demonstrated at least 1 instance of visible fluorescence during surgery. Visible fluorescence evaluated on a specimen-by-specimen basis yielded a diagnostic accuracy of $38.0 \%$ (cutoff threshold: visible fluorescence score $\geq 1$, area under the curve $=0.514$ ). Quantitative fluorescence yielded a diagnostic accuracy of $67 \%$ (for a cutoff threshold of the concentration of $\mathrm{PpIX}\left[\mathrm{C}_{\mathrm{Pp|X}}\right]>0.0056 \mu \mathrm{g} / \mathrm{ml}$, area under the curve $\left.=0.66\right)$. The authors found that $45 \%$ (9/20) of nonvisibly fluorescent tumor specimens, which would have otherwise gone undetected, accumulated diagnostically significant levels of $\mathrm{C}_{\mathrm{PplX}}$ that were detected quantitatively.

CONCLUSIONS The authors' initial experience with ALA-induced PpIX fluorescence in LGGs concurs with other literature reports that the resulting visual fluorescence has poor diagnostic accuracy. However, the authors also found that diagnostically significant levels of $\mathrm{C}_{\mathrm{PpIX}}$ do accumulate in LGGs, and the resulting fluorescence emissions are very often below the detection threshold of current visual fluorescence imaging methods. Indeed, at least in the authors' initial experience reported here, if quantitative detection methods are deployed, the diagnostic performance of ALA-induced PpIX fluorescence in LGGs approaches the accuracy associated with visual fluorescence in HGGs.

http://thejns.org/doi/abs/10.3171/2014.12.JNS14391

KEY WORDS low-grade glioma; fluorescence-guided surgery; protoporphyrin IX; 5-aminolevulinic acid; optical spectroscopy; quantitative fluorescence; brain tumor; biomedical optics; oncology

ABBREVIATIONS ALA = 5-aminolevulinic acid; $A U C=$ area under the curve; $C_{P p I X}=$ concentration of PpIX; HGG = high-grade glioma; $L G G=$ low-grade glioma; $N P V=$ negative predictive value; PpIX = protoporphyrin IX; PPV = positive predictive value; $R O C=$ receiver operating characteristic.

SUBMITTED April 12, 2014. ACCEPTED December 12, 2014.

INCLUDE WHEN CITING Published online July 3, 2015; DOI: 10.3171/2014.12.JNS14391.

DISCLOSURE This work was supported in part by NIH grant R01NS052274-04 (D.W.R.) awarded by the National Institute of Neurological Disorders and Stroke and K25CA138578 (F.L.) awarded by the National Cancer Institute. Carl Zeiss (Carl Zeiss Surgical GmbH) and Medtronic Navigation (Medtronic) provided the fluorescenceenabled OPMI Pentero operating microscope and StealthStation Treon navigation system, respectively. DUSA Pharmaceuticals (DUSA Pharmaceuticals) supplied the ALA Dr. Roberts served as a consultant for Medtronic Think Tanks (2012), for Zeiss Think Tanks (2012 and 2013), for a Scientific Advisory Board for an unrelated Alcyone study, for a Scientific Advisory Board for an unrelated IMRIS/SYMBIS study, for Zeiss's Neurosurgery Advisory Board, and on the Data Monitoring Committee for an unrelated Medtronic deep brain stimulation study. Drs. Valdés, Wilson, Leblond, Paulsen, and Roberts have multiple patent applications on several aspects of the quantitative fluorescence technologies discussed in this study. Dr. Paulsen is a patent holder with Dartmouth. 
$\mathrm{G}$ LIOMAS account for more than $70 \%$ of all primary brain tumors. ${ }^{6}$ Low-grade gliomas (LGGs) in particular (WHO Grades I and II) account for a variety of subtypes based on histological appearance, including diffuse astrocytomas, pilocytic astrocytomas, oligodendrogliomas, gangliogliomas, and oligoastrocytomas. ${ }^{22}$ Retrospective studies of long-term data suggest that gross-total resection is associated with significantly improved progression-free and overall survival within this population. ${ }^{18,31,33}$ In some instances of LGGs, complete resection can even be curative in these patients.

Tumor biomarkers that can be detected during intraoperative procedures hold promise for assisting and enabling further extent of resection. ${ }^{51}$ Specifically, several clinical trials have considered protoporphyrin IX (PpIX) - an endogenous fluorescent biomarker that can be visually detected under violet-blue light excitation following exogenous administration of 5-aminolevulinic acid (ALA) for fluorescence-guided resection. . $^{1,21,23,26,28,35-37,43,52}$ Importantly, the use of ALA-induced PpIX has improved complete resection and has led to statistically significant increases in progression-free survival in a randomized, controlled Phase III clinical trial of high-grade gliomas (HGGs). ${ }^{23,35-37}$

Despite these positive outcomes in HGGs, early experience with ALA-induced PpIX fluorescence in LGGs has been much more negative because these tumors have not been nearly as visually fluorescent as their HGG counterparts. ${ }^{1,7,10,11,13,15,17,20,29,30,34,35,41,47,49,52}$ However, the vast majority of clinical studies on fluorescence-guided neurosurgery have only considered the qualitative, visible PpIX emissions. In these investigations, a surgical microscope modified for fluorescence imaging is typically deployed and provides a violet-blue light excitation mode $(\lambda=405$ $\mathrm{nm})$ with fluorescence collection via a long-pass filter $(\lambda$ $=450-720 \mathrm{~nm})$. The emitted red-pink fluorescence $(\lambda=$ $610-720 \mathrm{~nm}$ ) is visualized through the surgical oculars or by image collection on a color camera integrated with the optics of the surgical microscope as an aid to identifying tumor for making resection decisions. ${ }^{26,35,38,49}$

We recently reported that significant levels of PpIX can be measured in a variety of brain tumor histologies, including LGGs, with an intraoperative probe that determines the actual PpIX concentration $\left(\mathrm{C}_{\mathrm{PpIX}}\right)$ in tissue from the fluorescence signal, even when no visual fluorescence is evident ${ }^{49}$ This method provides an objective measurement of tissue fluorescence that minimizes distortions caused by tissue optical properties and separates contributions from tissue autofluorescence, thereby reducing the subjectivity introduced by the observer's (i.e., the surgeon's) visual perception. ${ }^{16,47,49}$ In this paper, we summarize our initial experience with ALA-induced PpIX fluorescence in LGGs and compare our early findings to other reports in the literature. Specifically, we show that our results with visual PpIX fluorescence are very consistent with those of others in that very little, if any, visual fluorescence occurs in LGGs. Importantly, however, we also show that diagnostically significant concentrations of PpIX are routinely found in nonvisibly fluorescent LGGs, which suggests that diagnostic accuracies comparable to those observed with state-of-the-art visible fluorescence imaging in $\mathrm{HGGs}^{26,39}$ may be possible, when quantitative methods are used to assess the surgical field.

\section{Methods \\ Study Characteristics}

Patient data analyzed in this study were collected as part of a broader enrollment of patients with a variety of tumor histologies. ${ }^{2,26,49}$ The protocol was approved by the institutional review board at Dartmouth, which oversees the participation of human subjects in research, and all participants signed an informed consent form. An oral dose of ALA (DUSA Pharmaceuticals) was prepared by dissolving $20 \mathrm{mg} / \mathrm{kg}$ in $100 \mathrm{ml}$ of water and was administered approximately 3 hours prior to induction of anesthesia. Preoperative, high-resolution, contrast-enhanced T1weighted or T2-weighted axial MR images were acquired and used for image-guided neuronavigation during each case.

\section{Surgical Procedure}

Patients were positioned in secure 3-point fixation. A StealthStation Treon image-guidance system (Medtronic) provided the neuronavigation following standard practice. A Zeiss OPMI Pentero surgical microscope (Carl Zeiss Surgical $\mathrm{GmbH}$ ) modified for excitation and visualization of PpIX fluorescence (i.e., having the BLUE 400 fluorescence imaging module) was also tracked and preoperative MRI was coregistered with the surgical field through scalp fiducials.

Resection was carried out following standard microsurgical technique. Typically, the surgeon alternated between white and violet-blue light-emitting modes to visualize fluorescence during the resection. Biopsy specimens were collected at various times during the case in regions displaying both PpIX-positive and PpIX-negative visual fluorescence within the preoperatively planned resection volume.

In some cases and when available, the surgeon placed an intraoperative probe on the tissue to be biopsied, and quantitative $\mathrm{C}_{\mathrm{PpIX}}$ measurements were recorded in triplicate and averaged. Control data were acquired from normal cortex that did not undergo resection during these procedures. The biopsied site was also assigned a qualitative visible fluorescence score from 0 to 3 as described previously $^{28}$ ( 0 , no fluorescence; 1 minimal fluorescence; 2 , moderate fluorescence; and 3, high fluorescence) based on the impression of the surgeon who was blinded to the quantitative probe results. Then, tissue specimens were placed in formalin for subsequent histopathological analysis. Resection was continued until the surgeon judged that no more tissue could be safely removed. Postoperatively, all patients underwent serial liver function tests to monitor possible changes in liver function, and skin photosensitivity precautions were followed as per protocol. ${ }^{26,48,49}$

\section{Intraoperative Probe}

The intraoperative probe for in vivo measurement of $\mathrm{C}_{\mathrm{PpIX}}$ was used as described previously. ${ }^{16,49}$ Briefly, it consists of 4 fiberoptic cables arranged linearly and encased in a stainless steel housing approximately $1.1 \mathrm{~mm}$ in outer 
diameter. The fiberoptic cables included 1 channel for light collection, which was connected to a subnanometer resolution spectrometer, 2 channels for white light illumination at different distances from the detector fiber, and 1 channel for 405-nm light illumination. A light transport algorithm was applied to the white light data to calculate the tissue optical properties explicitly-information that corrects the raw fluorescence signal for variations caused by tissue light scattering and absorption. The attenuation correction enables quantitative values of $\mathrm{C}_{\mathrm{PpIX}}$ to be estimated by accounting for the nonlinear, attenuating effects caused by varying tissue optical properties at the measurement locations. ${ }^{16,49}$

\section{Pathology}

A histopathological analysis of formalin-fixed, paraffin-embedded tissue was performed by a neuropathologist (B.T.H.) who was blinded to the quantitative and qualitative fluorescence data. Biopsy specimens were classified based on WHO grading criteria, and results were tabulated by matching each specimen with its corresponding histopathological evaluation, qualitative visual fluorescence score, and quantitative fluorescence (i.e., $\mathrm{C}_{\mathrm{PpIX}}$ ) characteristics acquired with the probe. ${ }^{26}$

\section{Data and Statistical Analysis}

Data processing was performed using MATLAB software (Version R2011b, The MathWorks, Inc.). Statistical analysis was conducted using Stata (version 12.0, StataCorp) where the 2-sided significance level was set at $\mathrm{p}<$ 0.05 . Mixed models with random effects for each individual were used to accommodate the acquisition of multiple samples per patient. $^{8}$ Receiver operating characteristic (ROC) curve analysis was used to assess the diagnostic performance of both qualitative and quantitative fluorescence as described previously., ${ }^{9,32}$

\section{Results \\ Patient Characteristics}

Study data were collected from 12 consecutive patients with LGGs (WHO Grades I and II) in our original institutional review board, which included 2 oligodendrogliomas, 2 gangliogliomas, 1 ependymoma, 3 dysembryoplastic neuroepithelial tumors (DNETs), 3 oligoastrocytomas, and 1 pleomorphic xanthoastrocytoma as summarized in Table 1. Of these 12 LGGs, 1 pleomorphic xanthoastrocytoma, 1 oligoastrocytoma, 1 ganglioglioma, 1 oligodendroglioma, and 1 ependymoma (5/12 or $42 \%)$ demonstrated some degree of positive visual fluorescence in the operating room (Table 1).

\section{Qualitative and Quantitative Fluorescence}

\section{Assessment of Intraoperative Qualitative, Visible Fluorescence}

Seventy-three biopsy specimens were collected from the 12 patients with LGG (range 1-11 specimens per patient) where the tissue (prebiopsy) was evaluated for its visual fluorescence characteristics. In terms of visible fluorescence, $82 \%$ (58/73) of the tissue locations sampled were negative (i.e., visible fluorescence score of 0 ). In tis-
TABLE 1. Patient characteristics

\begin{tabular}{|c|c|c|c|}
\hline $\begin{array}{c}\text { Case } \\
\text { No. }\end{array}$ & Histology & $\begin{array}{c}\text { Probe } \\
\text { Quantitative } \\
\text { Fluorescence }\end{array}$ & $\begin{array}{c}\text { Visual } \\
\text { Fluorescence }\end{array}$ \\
\hline \multicolumn{4}{|l|}{ WHOI } \\
\hline 1 & DNET & - & - \\
\hline 2 & DNET & - & - \\
\hline 3 & Ganglioglioma & - & - \\
\hline 4 & DNET & - & - \\
\hline 5 & Ganglioglioma & + & + \\
\hline \multicolumn{4}{|l|}{ WHO II } \\
\hline 6 & $\begin{array}{l}\text { Pleomorphic xanthoatrocy- } \\
\text { toma }\end{array}$ & - & + \\
\hline 7 & Oligoastrocytoma & + & + \\
\hline 8 & Oligoastrocytoma & + & - \\
\hline 9 & Oligodendroglioma & - & + \\
\hline 10 & Oligodendroglioma & + & - \\
\hline 11 & Oligoastrocytoma & + & - \\
\hline 12 & Ependymoma & + & + \\
\hline
\end{tabular}

sue samples histologically graded as nontumor, $19 \%$ (4/21) exhibited visible fluorescence (all 4 samples with a visual fluorescence score of 2; false positive) and 81\% (17/21) were negative for visible fluorescence (visible fluorescence score of 0 ; true negative). In tumor samples, 79\% (41/52) did not exhibit visible fluorescence (visible fluorescence score of 0 ; false negative) and 21\% (11/52) were positive for visible fluorescence (visible fluorescence score $>0$; true positive).

\section{Relationship Between Intraoperative Visible Fluorescence and $\mathrm{C}_{\text {PplX }}$}

In 6 of the 12 surgeries, the intraoperative probe was available for data collection, and 36 tissue locations were sampled. From this information, relationships between visual and nonvisual fluorescence and $\mathrm{C}_{\mathrm{PpIX}}$ for specimens histologically graded as positive and negative for tumor were constructed as shown in Fig. 1. Visually, 86\% (31/36) of the tissue locations that were sampled did not demonstrate fluorescence. In tissue sites categorized as nontumor, $8.3 \%$ (1/12) exhibited visible fluorescence. In those specimens histologically graded as tumor, 83\% (20/24) were not visibly fluorescent. The oligoastrocytoma, oligodendroglioma, and ganglioglioma cases with positive visible fluorescence were more heterogeneous (in terms of visible fluorescence) relative to their ependymoma and pleomorphic xanthoastrocytoma counterparts, which exhibited a brighter, more homogeneous, visible fluorescence within the tumor bulk. Figure 2 presents an overview of the individual measurements across the various LGG histologies.

In this study, nonvisibly fluorescent tissue presented with a median $\mathrm{C}_{\mathrm{PpIX}}$ of $0.004 \mu \mathrm{g} / \mathrm{ml}$ (minimum: $0.000 \mu \mathrm{g}$ / $\mathrm{ml}$; 25th percentile: $0.000 \mu \mathrm{g} / \mathrm{ml}$; 75th percentile: 0.022 $\mu \mathrm{g} / \mathrm{ml}$; maximum: $0.205 \mu \mathrm{g} / \mathrm{ml}$ ) and mean $\mathrm{C}_{\mathrm{PpIX}}$ of 0.034 $\mu \mathrm{g} / \mathrm{ml}$ (SD $0.064 \mu \mathrm{g} / \mathrm{ml}$ ), whereas visibly fluorescent tissue produced a median $\mathrm{C}_{\mathrm{PpIX}}$ of $3.161 \mu \mathrm{g} / \mathrm{ml}$ (minimum: 


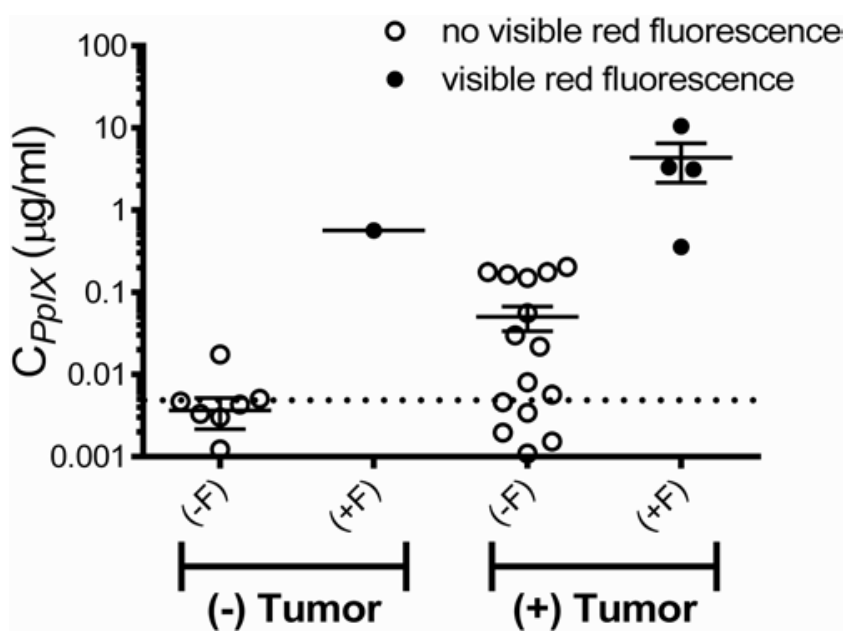

FIG. 1. Intraoperative fluorescence in 6 LGGs interrogated with the quantitative probe: $C_{P p \mid X}$ in specimens histologically categorized as either tumor negative, (-) Tumor, or tumor positive, (+) Tumor, with no visible fluorescence, $(-F)$, or positive visible fluorescence, $(+F)$. Nonvisibly fluorescent tumor tissues (45\%, 9/20 specimens) accumulated levels of $\mathrm{C}_{\mathrm{PplX}}$ (cutoff value $>0.0056 \mu \mathrm{g} / \mathrm{ml}$ ) that were not identified with intraoperative visible fluorescence imaging. The one false positive for visible fluorescence (-Tumor, $+\mathrm{F}$ ) was from a sample of brightly visibly fluorescent normal hippocampus.

$0.356 \mu \mathrm{g} / \mathrm{ml} ; 25$ th percentile: $0.461 \mu \mathrm{g} / \mathrm{ml}$; 75 th percentile: $6.930 \mu \mathrm{g} / \mathrm{ml}$; maximum: $10.5 \mu \mathrm{g} / \mathrm{ml}$ ) and a mean $\mathrm{C}_{\mathrm{PpIX}}$ of $3.589 \mu \mathrm{g} / \mathrm{ml}$ (SD $4.127 \mu \mathrm{g} / \mathrm{ml}$ ). Visibly fluorescent tissue demonstrated a statistically significant increase in $\mathrm{C}_{\mathrm{P} p I X}$ levels when compared with nonvisibly fluorescent tissue ( $p<0.001)$. Normal tissue (i.e., gray and white matter) presented with a median $\mathrm{C}_{\mathrm{PpIX}}$ of $0.003 \mu \mathrm{g} / \mathrm{ml}$ (minimum: $0.000 \mu \mathrm{g} / \mathrm{ml} ; 25$ th percentile: $0.001 \mu \mathrm{g} / \mathrm{ml} ; 75$ th percentile: $0.005 \mu \mathrm{g} / \mathrm{ml}$; maximum: $0.567 \mu \mathrm{g} / \mathrm{ml}$ ) and a mean $\mathrm{C}_{\mathrm{PpIX}}$ of $0.051 \mu \mathrm{g} / \mathrm{ml}$ (SD $0.163 \mu \mathrm{g} / \mathrm{ml}$ ), while tumor had a median $C_{\mathrm{PpIX}}$ of $0.015 \mu \mathrm{g} / \mathrm{ml}$ (minimum: $0.000 \mu \mathrm{g} / \mathrm{ml}$; 25th percentile: $0.001 \mu \mathrm{g} / \mathrm{ml}$; 75 th percentile: $0.177 \mu \mathrm{g} / \mathrm{ml}$; maximum: $10.540 \mu \mathrm{g} / \mathrm{ml}$ ) and mean $\mathrm{C}_{\text {Ppix }}$ of $0.766 \mu \mathrm{g} / \mathrm{ml}$ (SD $2.268 \mu \mathrm{g} / \mathrm{ml}$ ) (Table 2). The data exhibited a large dynamic range between 0.000 and $10.5 \mu \mathrm{g} / \mathrm{ml}$.

\section{Diagnostic Analysis of Qualitative and Quantitative Fluorescence in LGG Subtypes}

As summarized in Table 3, ROC analysis of all 12 LGGs $(n=12)$ based on visible fluorescence yielded a diagnostic accuracy of $38 \%$ (cutoff threshold: visible fluorescence score of $\geq 1$, area under the curve [AUC] of 0.52 ), sensitivity of $21 \%$, negative predictive value (NPV) of $29 \%$, specificity of $81 \%$, and positive predictive value (PPV) of $73 \%$. A corresponding analysis of quantitative fluorescence measured with the probe yielded a diagnostic accuracy of $67 \%$ (cutoff threshold of $0.0057 \mu \mathrm{g} / \mathrm{ml}$, AUC of 0.663 ), sensitivity of $58 \%$, NPV of $50 \%$, specificity of $83 \%$, and PPV of $87 \%$.

Figure 3 illustrates the advantages of quantitative versus visual fluorescence in the 2 cases of oligoastrocytomas, which presented with different visible fluorescence characteristics. First, the results indicate that tumor tissue can accumulate 10-1000 times more $\mathrm{C}_{\mathrm{P} \text { IX }}$ than normal cortex (Fig. 3A-D). Two instances of nonvisibly fluorescent tumor tissue-one in the bulk mass (Fig. 3E-H) and the other at the margin (Fig. 3I-L) - appear in Fig. 3. The latter case of histopathologically confirmed tumor accumulated approximately 150 times more $\mathrm{C}_{\mathrm{PpIX}}$ than normal cortex and identified tumor outside the border of the preoperative T2 MRI signal abnormality in the image-guided view. Figure $3 \mathrm{M}-\mathrm{O}$ shows a case of oligoastrocytoma where visible fluorescence was present within the tumor bulk and outside the region of contrast enhancement, suggesting, again, the complementary value of PpIX fluorescence for guiding resection decisions.

\section{Discussion}

Most studies to date have empirically concluded that significant levels of PpIX accumulate in HGGs because

- no visible red fluorescence

- visible red fluorescence

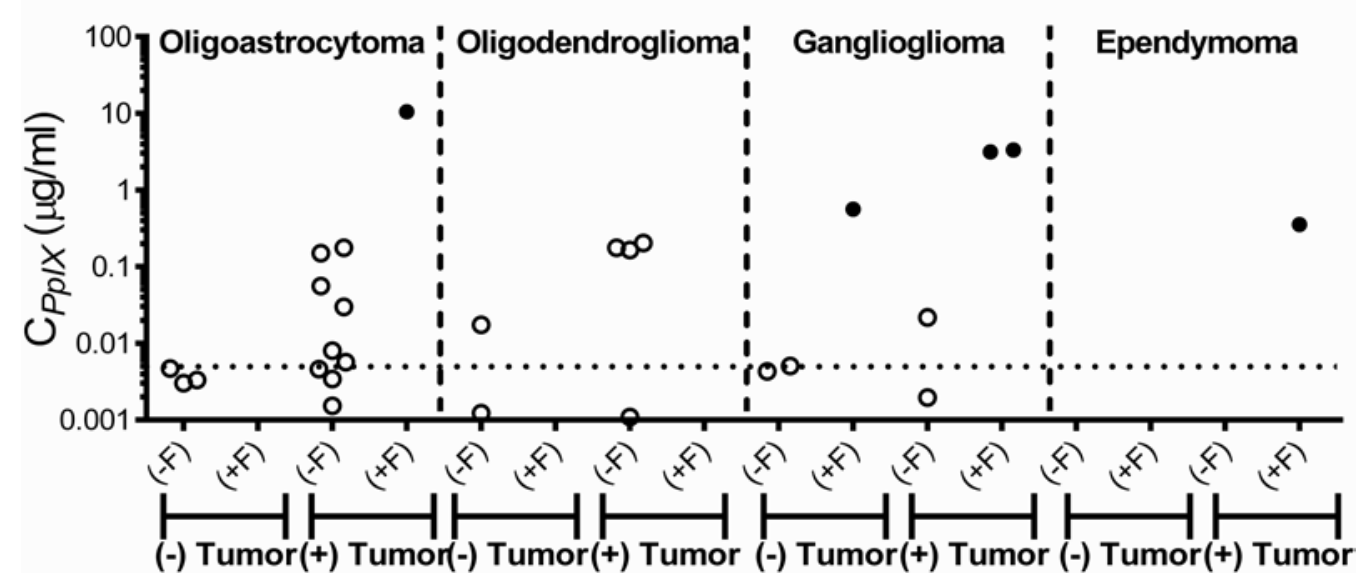

FIG. 2. Intraoperative fluorescence using the quantitative probe in LGG subtypes: $C_{\mathrm{PpIX}}$ in specimens categorized as either tumor negative, (-) Tumor, or tumor positive, $(+)$ Tumor, with no visible fluorescence, $(-F)$, or positive visible fluorescence, $(+F)$, in each category. Nine data points with $\mathrm{C}_{\mathrm{PpIX}}<0.001 \mu \mathrm{g} / \mathrm{ml}$ are not displayed: oligoastrocytoma: 3 (-F, -Tumor) and 3 (-F, +Tumor); oligodendroglioma: 1 (-F, -Tumor) and 1 (-F, +Tumor); and ganglioglioma: 1 (-F, +Tumor). 
TABLE 2. Protoporphyrin IX $\left(C_{\mathrm{PpIX}}\right)$ levels in LGGs

\begin{tabular}{lccccccc}
\hline \multicolumn{1}{c}{ Tissue Type } & Mean & SD & Minimum & 25th Percentile & Median & 75th Percentile & Maximum \\
\hline Nonvisibly fluorescent tissue & 0.034 & 0.064 & 0.000 & 0.000 & 0.004 & 0.022 & 0.205 \\
\hline Visibly fluorescent tissue & 3.589 & 4.127 & 0.356 & 0.461 & 3.161 & 6.930 & 10.540 \\
\hline Normal tissue & 0.051 & 0.163 & 0.000 & 0.001 & 0.003 & 0.005 & 0.567 \\
\hline Tumor & 0.766 & 2.268 & 0.000 & 0.001 & 0.015 & 0.177 & 10.540 \\
\hline
\end{tabular}

* All values are $\mu \mathrm{g} / \mathrm{ml}$.

the fluorescence emissions caused by blue light exposure are visible during these resections. . $^{, 5,10-12,23,24,26-28,35-37,39,40,43}$ This experience culminated in a randomized Phase III clinical trial in Europe, which demonstrated that fluorescence-guided surgery essentially doubled the rate of complete resection relative to white light surgical guidance alone.

In this study, we compared our initial experience with visual and quantitative fluorescence in LGGs because of the limited literature that exists $1,7,10,11,13,15,17,20,29,30,34,35,41,47,49,52$ and the general consensus within the neurosurgical community that PpIX is not a useful biomarker for fluorescence guidance in LGG resection. Table 4 summarizes the literature associated with ALA-induced PpIX fluorescence in primary LGGs (WHO Grade I and II) from 13 studies involving 90 patients. The reported histologies included astrocytoma, oligodendroglioma, oligoastrocytoma, dysembryoplastic neuroepithelial tumor, pilocytic astrocytoma, pleomorphic xanthoastrocytoma, ganglioglioma, and otherwise unspecified WHO Grade I or II tumors. In these data, $16 \%$ of the cases (14/90 cases) showed at least 1 instance of intraoperative visible fluorescence. No visible fluorescence was reported in all 15 WHO Grade I cases. In the WHO Grade II histologies, 19\% (14/75) demonstrated visible fluorescence and consisted of $15 \%$ of astrocytomas (WHO Grade II) (8/52), 21\% (3/14) of oligoastrocytomas, $25 \%(2 / 8)$ of oligodendrogliomas, and $100 \%$ (1/1) of pleomorphic xanthoastrocytomas. Two studies involving a contact optical spectroscopy probe reported by Utsuki et al. ${ }^{41}$ and Montcel et al. ${ }^{20}$ did not elaborate in detail on the tumor histologies and visible levels of intraoperative PpIX fluorescence that were found in a total of 6 and 2 cases, respectively, and as a result these data were not included in

TABLE 3. Diagnostic performance of ALA-induced PpIX fluorescence in LGGs

\begin{tabular}{lll}
\hline \multicolumn{1}{c}{ Parameter } & $\begin{array}{c}\text { Qualitative, Visible } \\
\text { Fluorescence }\end{array}$ & $\begin{array}{c}\text { Quantitative } \\
\text { Fluorescence }\end{array}$ \\
\hline No. of patients & 12 & 6 \\
\hline No. of specimens & 73 & 36 \\
\hline Classification efficiency & 38.0 & 66.7 \\
\hline ROC (AUC) & 0.514 & 0.663 \\
\hline CO & $\geq 1($ visible score) & $0.0057(\mu \mathrm{g} / \mathrm{ml})$ \\
\hline Sensitivity (\%) & 21.1 & 58.3 \\
\hline NPV (\%) & 29.8 & 50.0 \\
\hline Specificity (\%) & 81.0 & 83.3 \\
\hline PPV (\%) & 73.0 & 87.5 \\
\hline
\end{tabular}

$\mathrm{CO}=$ cutoff threshold. this analysis of the literature. In cases in which visible fluorescence was observed during LGG surgery, the literature reports did not describe the proportion of locations and samples that exhibited visible fluorescence; some studies consisted of surgical biopsy cases and only discussed 1 or 2 specimens (e.g., Ewelt et al., ${ }^{7}$ Floeth et al., ${ }^{10}$ and Widhalm et al. ${ }^{52}$ ). The available literature indicates that only a small percentage of LGGs $(16 \%$ for all LGGs, $0.0 \%$ of WHO Grade I, and 19\% of WHO Grade II) demonstrate any intraoperative visible fluorescence, which is consistent with our experience and the view that ALA-induced PpIX fluorescence is not a viable biomarker for LGG surgical guidance when using visual techniques-either the naked eye or current state-of-the-art visible fluorescence technologies (e.g., Zeiss Pentero BLUE 400).

Sanai et al. ${ }^{30}$ described the use of an intraoperative confocal microscopy probe for microscopic visualization of PpIX in LGGs. They reported no visible fluorescence in their experience (Table 4), but the confocal microscopy probe detected PpIX in LGGs on a cellular level. This method does not offer a quantitative approach to fluorescence-guided surgery per se, but the imaging does improve sensitivity to PpIX in LGGs and allows a subjective assessment of the confocal images. Utsuki et al. ${ }^{41}$ described application of a spectroscopy system through which they found significant signal in a subset of LGGs by identifying a PpIX peak at $636 \mathrm{~nm}$. Studies have reported levels of PpIX in tumor tissue using ex vivo techniques. For example, we published an ex vivo fluorimetry method to measure absolute PpIX levels in tumor specimens ${ }^{46}$ with WHO Grade I-IV gliomas and found that approximately $40 \%$ of tumor-positive biopsy sites that were not visibly fluorescent had $\mathrm{C}_{\mathrm{PpIX}}>0.100 \mu \mathrm{g} / \mathrm{ml}$, including significant $\mathrm{C}_{\mathrm{PpIX}}$ levels in both visibly and nonvisibly fluorescent LGGs.

In a prior study ${ }^{49}$ we first described the use of the quantitative probe on a variety of tumor histologies, including LGGs and HGGs, meningiomas, and metastases. We showed that across these various tumor types, diagnostic levels of PpIX could be quantitatively measured in both visibly and nonvisibly fluorescent tumor. In contrast to the present study, in the earlier work we looked at a variety of tumor types and only 2 LGG cases. Here, we present our experience exclusively on 12 LGGs and provide a specific analysis of our experience comparing results using both visible and quantitative fluorescence techniques. This work provides evidence that a quantitative technique for PpIX fluorescence guidance may enhance the surgeon's ability to detect tumor tissue beyond what is currently capable with visible fluorescence techniques.

In the study reported here, 5 of 12 LGGs (1 gangliogli- 

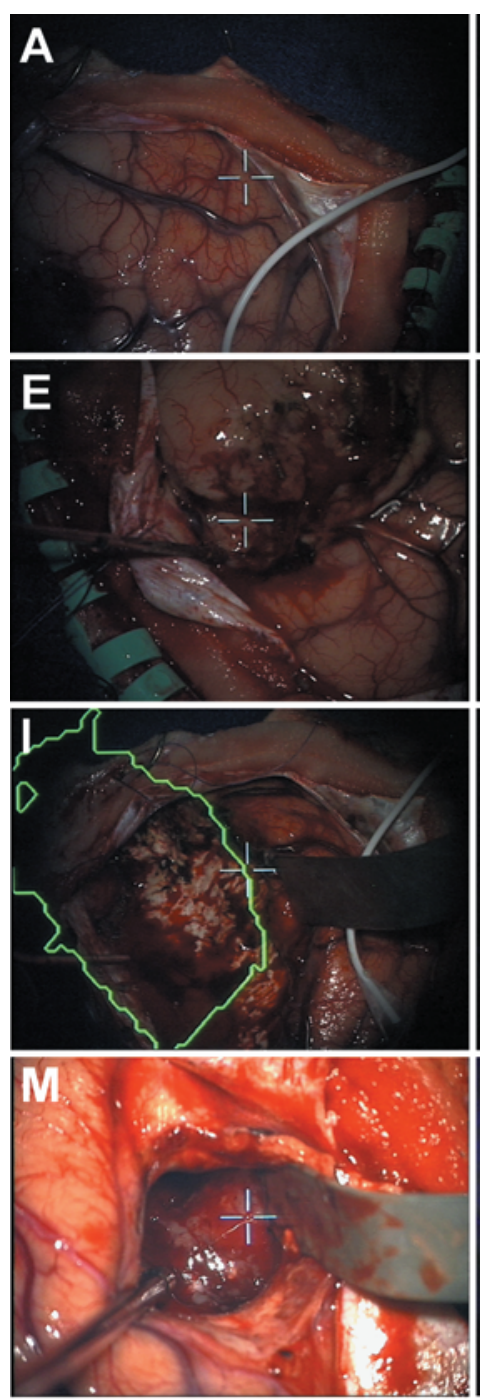
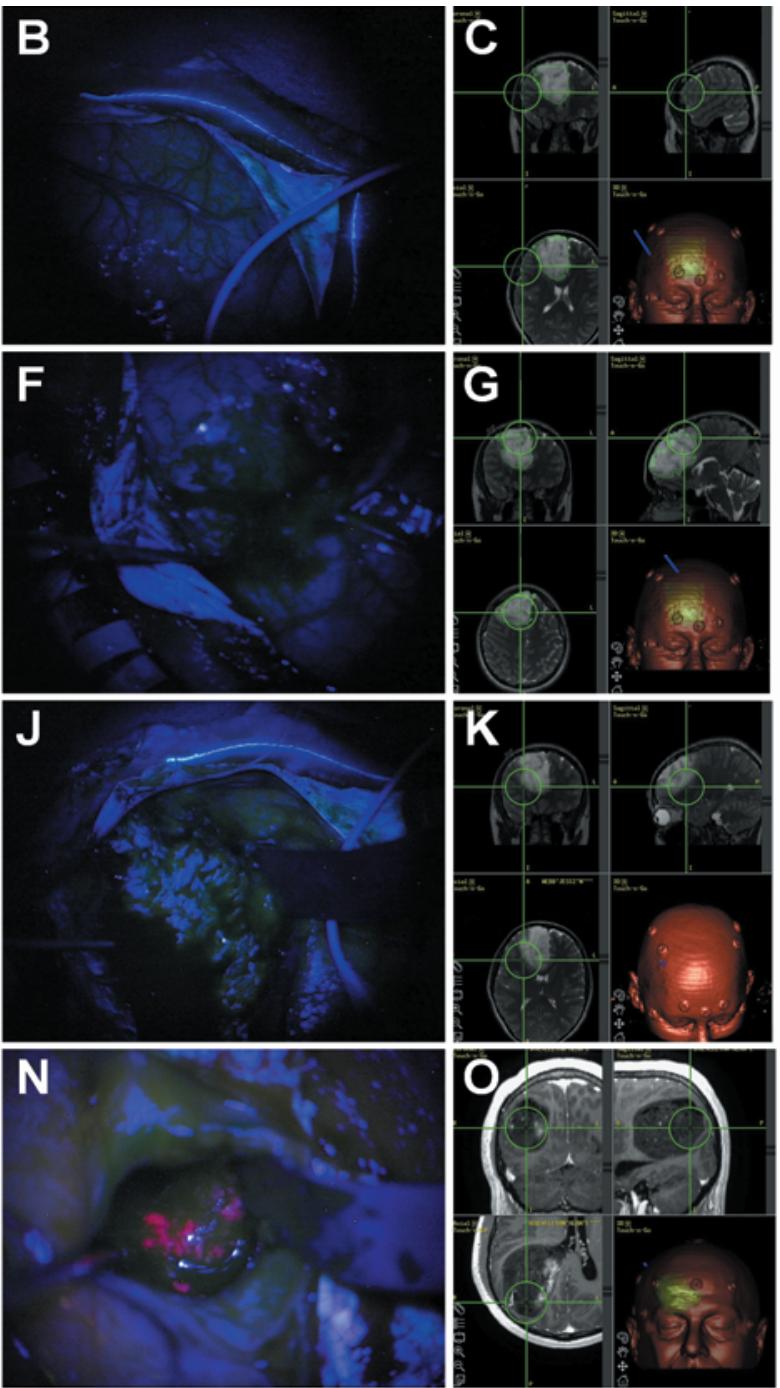
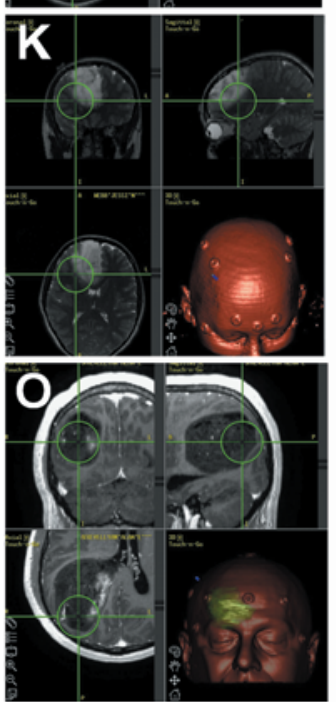
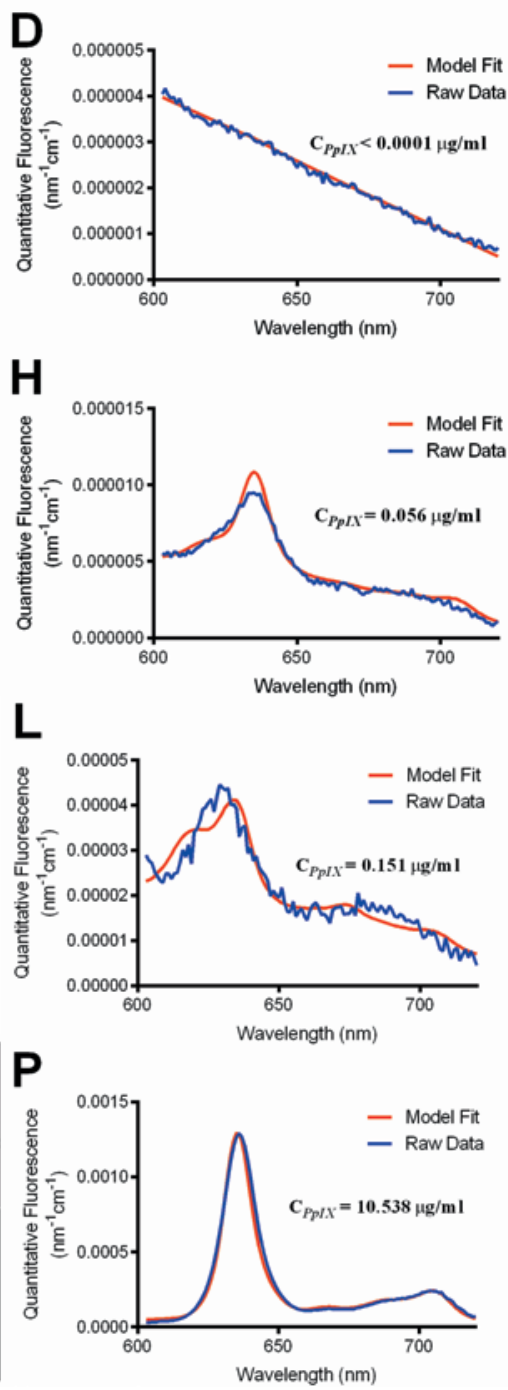

FIG. 3. Intraoperative quantitative and qualitative measurements of PpIX during 2 oligoastrocytoma surgical cases with differing visible fluorescence characteristics. Normal cortex under white light $(\mathbf{A})$, violet-blue light excitation demonstrating no visible fluorescence (B), neuronavigation coordinates at the cortical surface far removed from the area of T2 hyperintensity (C), and quantitative spectroscopic probe measurements demonstrating a typical autofluorescence spectrum without signs of the signature PpIX main peak at $635 \mathrm{~nm}$ (D). Surgical cavity of one oligoastrocytoma under white light (E), violet-blue light excitation with no visible fluorescence $(\mathbf{F})$, neuronavigation coordinates at the T2 hyperintensity region within the tumor bulk (G), and quantitative spectroscopic probe measurements $(\mathbf{H})$ with the typical PpIX main peak at $635 \mathrm{~nm}$ and approximately 50 times more PpIX than normal cortex, and again near the end of surgery under white light (I), violet-blue light excitation with no visible fluorescence (J), neuronavigation coordinates at the T2 hyperintensity preoperative MRI border (K), and quantitative spectroscopic probe measurements with the typical PpIX main peak at $635 \mathrm{~nm}$ and approximately 150 times more PpIX than normal cortex (L). Surgical cavity of another oligoastrocytoma that demonstrated visible fluorescence under white light (M), violet-blue light excitation illustrating visible fluorescence $(\mathbf{N})$, neuronavigation coordinates within the tumor bulk near a region of contrast enhancement on T1-weighted MRI (O), and quantitative spectroscopic probe measurements (P) of a spectrum with the typical PpIX main peak at $635 \mathrm{~nm}$ and $710 \mathrm{~nm}$ and approximately 10,000 times more PpIX than normal cortex.

oma, 1 oligoastrocytoma, 1 pleomorphic xanthoastrocytoma, 1 oligodendroglioma, and 1 ependymoma) included at least 1 site of visible fluorescence during surgery, which is consistent with the data in the literature (Table 4), suggesting that the minority of LGGs accumulate sufficient levels of PpIX to overcome the attenuating effects of tissue optical properties and enable visualization of the fluorescence. The low diagnostic accuracy is mainly the result of the low sensitivities and low NPVs (sensitivity of $21 \%$, NPV of $29 \%$; Table 3) derived from the data.
In the tissue samples from the 6 LGGs that underwent evaluation with both visible and quantitative fluorescence techniques, $\mathrm{C}_{\mathrm{PpIX}}$ in normal cortex was approximately $0.001 \mu \mathrm{g} / \mathrm{ml}$, whereas $45 \%(9 / 20)$ of the nonvisibly fluorescent tumor specimens accumulated $\mathrm{C}_{\mathrm{PpIX}}$ levels greater than $0.0056 \mu \mathrm{g} / \mathrm{ml}$ (the cutoff value used in the ROC analysis), suggesting that a sizable fraction of LGGs is likely to accumulate significant levels of $\mathrm{C}_{\mathrm{PpIX}}$ (approximately 10-1000 times more than normal brain tissue) that are not visibly fluorescent. 
TABLE 4. LGGs and 5-ALA-induced PpIX fluorescence in the literature

\begin{tabular}{|c|c|c|c|c|}
\hline Grade \& Tumor Histology & Total & $(+) v F I$ & $(-) \mathrm{vFI}$ & Authors \& Year \\
\hline \multicolumn{5}{|l|}{ WHOI } \\
\hline Astrocytoma & 3 & 0 & 3 & Marbacher et al., 2014 \\
\hline DNET & 3 & 0 & 3 & Valdés et al., $2011^{47}$ \\
\hline Ganglioglioma & 1 & 0 & 1 & Valdés et al., $2011^{47}$ \\
\hline Pilocytic astrocytoma & 7 & 0 & 7 & Beez et al., 2014 \\
\hline DNET & 1 & 0 & 1 & Sanai et al., 2011 \\
\hline \multicolumn{5}{|l|}{ WHO II } \\
\hline Astrocytoma & 12 & 5 & 7 & Marbacher et al., 2014 \\
\hline Astrocytoma & 11 & 1 & 10 & Ewelt et al., 2011 \\
\hline Astrocytoma & 4 & 0 & 4 & Widhalm et al., 2010 \\
\hline Astrocytoma & 14 & 1 & 13 & Floeth et al., 2011 \\
\hline Astrocytoma & 1 & 1 & 0 & Stockhammer et al., 2009 \\
\hline Astrocytoma & 2 & 0 & 2 & Ishihara et al., 2007 \\
\hline Astrocytoma & 4 & 0 & 4 & Hefti et al., 2008 \\
\hline Astrocytoma & 4 & 0 & 4 & Sanai et al., 2011 \\
\hline Oligoastrocytoma & 2 & 1 & 1 & Valdés et al., $2012^{48,50}$ \\
\hline Oligoastrocytoma & 3 & 1 & 2 & Marbacher et al., 2014 \\
\hline Oligoastrocytoma & 2 & 1 & 1 & Valdés et al., $2011^{47}$ \\
\hline Oligoastrocytoma & 1 & 0 & 1 & Ewelt et al., 2011 \\
\hline Oligoastrocytoma & 3 & 0 & 3 & Widhalm et al., 2010 \\
\hline Oligoastrocytoma & 2 & 0 & 2 & Floeth et al., 2011 \\
\hline Oligoastrocytoma & 1 & 0 & 1 & Sanai et al., 2011 \\
\hline Oligodendroglioma & 2 & 2 & 0 & Marbacher et al., 2014 \\
\hline Oligodendroglioma & 1 & 0 & 1 & Ewelt et al., 2011 \\
\hline Oligodendroglioma & 1 & 0 & 1 & Widhalm et al., 2010 \\
\hline Oligodendroglioma & 3 & 0 & 3 & Sanai et al., 2011 \\
\hline Oligodendroglioma & 1 & 0 & 1 & Floeth et al., 2011 \\
\hline Pleomorphic xanthoastrocytoma & 1 & 1 & 0 & Ruge \& Liu, 2009 \\
\hline
\end{tabular}

In an analysis of diagnostic performance across all LGG subtypes combined, quantitative fluorescence demonstrated a diagnostic accuracy of $67 \%$ (cutoff threshold of $0.0056 \mu \mathrm{g} / \mathrm{ml}$, AUC of 0.663) with improved sensitivity and NPV (sensitivity of 58\%, NPV of 50\%) as well as specificity and PPV (specificity of $83 \%$ and PPV of $87 \%$ ) compared with visible fluorescence (Table 3). Interestingly, the diagnostic performance of quantitative fluorescence in this small cohort of LGG patients is approaching that reported in the literature for qualitative, visible fluorescence in HGGs when a modified surgical microscope for fluorescence imaging is deployed.

Recently, spectroscopic probes have received increased attention as tools for intraoperative fluorescence identification. ${ }^{12,15,19,20,39,41,42,47,49,50}$ Spectroscopic analysis allows positive identification of the typical PpIX fluorescence spectrum with its major peak at $635 \mathrm{~nm}$ and a second minor peak at $710 \mathrm{~nm}$, and enables improved detection of diagnostically significant levels of PpIX (i.e., above autofluorescence) in tissues that do not demonstrate visible fluorescence. ${ }^{12,39,42,49}$ Spectroscopic probes increase sensitivity primarily by improving the efficiency of light excitation and detection relative to wide-field fluorescence imaging.
However, an important distinction should be drawn between these spectroscopic probe studies and the present work, in that most published reports ${ }^{12,19,39,41}$ use the "raw" fluorescence signal to infer the diagnostic performance of the fluorophore. Although these probes may offer more sensitivity to PpIX fluorescence than the visual widefield imaging that is commercially available through the fluorescence-adapted operating microscope, these probe measurements are semiquantitative ${ }^{44}$ and do not account for the variable attenuation caused by tissue optical properties on the detected fluorescence, $, 16,25,28,44,49,50$ and therefore, do not calculate the absolute fluorescent biomarker concentrations. In the case of quantitative methods (e.g., the quantitative probe used here), the absolute fluorophore (i.e., PpIX) concentration is obtained, ${ }^{16,49}$ such that the ROC curves and diagnostic thresholds are absolute and observer or spectroscopy probe independent.

Low-grade gliomas are often grouped together based on their treatment management and prognosis; yet, they represent a variety of pathological and molecular phenotypes. ${ }^{14}$ Given expected variations in tumor biology and histopathology and our findings of some variation in $\mathrm{C}_{\mathrm{PpIX}}$ across the LGG subtypes evaluated here (Fig. 2), the diagnostic 
performance of $\mathrm{C}_{\mathrm{PpIX}}$ is likely to vary by LGG subtype. This result suggests the development of more specific biomarkers is needed that would target these tumor histopathologies explicitly.

Here, we present our experience using quantitative fluorescence in a small cohort of LGGs, noting that a more sensitive and quantitative approach can provide improved diagnostic capabilities and overall surgical guidance for the resection of LGGs. More specifically, we were able to detect diagnostically significant quantitative concentrations of PpIX in nonvisibly fluorescent tumor tissue, which was 10-100 times greater than that in normal parenchyma. This report further elucidates a technique that provides the community with a means for improved detection of nonenhancing, nonvisibly fluorescent, e.g., negative on the Zeiss Pentero microscope, LGG tissue using PpIX as a tumor biomarker. Second, we also present an overview of the available literature using PpIX as a biomarker for LGGs. We note the limited diagnostic value of current visible PpIX fluorescence imaging and as such, recommend a need for a more sensitive technique.

In the context of supramarginal resection and/or functional imaging, this tool would provide the surgeon with additional information regarding the presence of tumor tissue within the grossly abnormal MRI regions (e.g., T2weighted abnormality) as well as of infiltrative disease that may not be clearly delineated on MRI. This additional information would help guide decision making, maximize resection of infiltrative disease, and minimize damage to normal parenchyma. This technique could serve as an added tool in the neurosurgical armamentarium for resection of LGGs.

A limitation of this study is the small number of patients (12) with LGGs that have been evaluated. We are currently recruiting more patients to further note the extent to which PpIX can serve as a biomarker in LGGs. Overall, the results are consistent with our previous data, ${ }^{49}$ which have demonstrated significant accumulation of PpIX across a range of tumor histologies, and the detection of nonvisibly fluorescent levels of $\mathrm{C}_{\mathrm{PpIX}}(>0.0056 \mu \mathrm{g} / \mathrm{ml})$ in tumor tissues, and specifically in LGGs. The low number and variety of LGG subtypes presented here should encourage future studies of PpIX as a fluorescent biomarker in LGGs with more sensitive and quantitative methods. Nevertheless, the results are significant because they counter the current opinion that PpIX does not accumulate in diagnostically significant concentrations in LGGs. Additionally, the biological reasons why some of the LGG cases evaluated here have such low levels of PpIX (that go undetected even with the quantitative spectroscopic probe) is unclear. The present study is also limited by the contact point probe that interrogates a small region of tissue (approximately $1 \mathrm{~mm}$ in diameter). In terms of future developments, we have recently reported a quantitative imaging system that enables real-time, highly sensitive measurements of $\mathrm{C}_{\mathrm{PpIX}}$ across the full surgical field of view with a diagnostic performance that is comparable in accuracy and sensitivity to the quantitative intraoperative probe readings. ${ }^{45,48}$ These results support the need for more accurate and quantitative technologies for PpIX detection. The new quantitative imaging system translates the principles demonstrated in this study using the quantitative probe to a full imaging setup, with further studies needed to validate its utility in the neurosurgical operating room. We have also found that the incorporation of additional biomarkers (e.g., oxy- and deoxy-hemoglobin and oxygen saturation) predictive of tissue histopathological processes (e.g., vascular density/ angiogenesis and oxygenation/hypoxia) associated with tumor leads to improved diagnostic performance when combined with $\mathrm{C}_{\mathrm{PpIX}}{ }^{47}$ and this multiparametric approach warrants further investigation.

\section{Conclusions}

Here, we present our initial experience with ALAinduced PpIX fluorescence in a series of 12 LGGs and compare the diagnostic performance of visual and quantitative fluorescence. The quantitative fluorescence data suggest that low, but diagnostically significant, levels of PpIX do accumulate in LGGs that are below the detection threshold of current visual fluorescence techniques. These results are potentially of great importance because an increased extent of resection in LGGs is more likely to have a substantial impact on patient survival relative to their HGG counterparts. This experience provides evidence that ALA-induced PpIX fluorescence-guided surgery may not be limited to HGGs provided that quantitative fluorescence methods are applied, and efforts to develop the requisite wide-field imaging technology should be pursued accordingly.

\section{Acknowledgment}

We thank Dr. Neda Haj-Hosseini for useful comments on our paper.

\section{References}

1. Beez T, Sarikaya-Seiwert S, Steiger HJ, Hänggi D: Fluorescence-guided surgery with 5-aminolevulinic acid for resection of brain tumors in children-a technical report. Acta Neurochir (Wien) 156:597-604, 2014

2. Bekelis K, Valdés PA, Erkmen K, Leblond F, Kim A, Wilson BC, et al: Quantitative and qualitative 5-aminolevulinic acidinduced protoporphyrin IX fluorescence in skull base meningiomas. Neurosurg Focus 30(5):E8, 2011

3. Bradley RS, Thorniley MS: A review of attenuation correction techniques for tissue fluorescence. J R Soc Interface 3:1-13, 2006

4. Colditz MJ, Jeffree RL: Aminolevulinic acid (ALA)-protoporphyrin IX fluorescence guided tumour resection. Part 1 : Clinical, radiological and pathological studies. J Clin Neurosci 19:1471-1474, 2012

5. Colditz MJ, Leyen Kv, Jeffree RL: Aminolevulinic acid (ALA)-protoporphyrin IX fluorescence guided tumour resection. Part 2: theoretical, biochemical and practical aspects. J Clin Neurosci 19:1611-1616, 2012

6. DeAngelis LM: Brain tumors. N Engl J Med 344:114-123, 2001

7. Ewelt C, Floeth FW, Felsberg J, Steiger HJ, Sabel M, Langen KJ, et al: Finding the anaplastic focus in diffuse gliomas: the value of Gd-DTPA enhanced MRI, FET-PET, and intraoperative, ALA-derived tissue fluorescence. Clin Neurol Neurosurg 113:541-547, 2011

8. Fitzmaurice GM, Laird NM, Ware JH: Applied Longitudinal Analysis. Hoboken, NJ: Wiley, 2004

9. Fitzmaurice M: Principles and pitfalls of diagnostic test de- 
velopment: implications for spectroscopic tissue diagnosis. J Biomed Opt 5:119-130, 2000

10. Floeth FW, Sabel M, Ewelt C, Stummer W, Felsberg J, Reifenberger G, et al: Comparison of (18)F-FET PET and 5-ALA fluorescence in cerebral gliomas. Eur J Nucl Med Mol Imaging 38:731-741, 2011

11. Floeth FW, Stummer W: The value of metabolic imaging in diagnosis and resection of cerebral gliomas. Nat Clin Pract Neurol 1:62-63, 2005

12. Haj-Hosseini N, Richter J, Andersson-Engels S, Wårdell K: Optical touch pointer for fluorescence guided glioblastoma resection using 5-aminolevulinic acid. Lasers Surg Med 42:9-14, 2010

13. Hefti M, von Campe G, Moschopulos M, Siegner A, Looser $\mathrm{H}$, Landolt $\mathrm{H}$ : 5-aminolevulinic acid induced protoporphyrin IX fluorescence in high-grade glioma surgery: a one-year experience at a single institution. Swiss Med Wkly 138:180 185,2008

14. Hirose Y, Sasaki H, Abe M, Hattori N, Adachi K, Nishiyama Y, et al: Subgrouping of gliomas on the basis of genetic profiles. Brain Tumor Pathol 30:203-208, 2013

15. Ishihara R, Katayama Y, Watanabe T, Yoshino A, Fukushima T, Sakatani K: Quantitative spectroscopic analysis of 5-aminolevulinic acid-induced protoporphyrin IX fluorescence intensity in diffusely infiltrating astrocytomas. Neurol Med Chir (Tokyo) 47:53-57, 2007

16. Kim A, Khurana M, Moriyama Y, Wilson BC: Quantification of in vivo fluorescence decoupled from the effects of tissue optical properties using fiber-optic spectroscopy measurements. J Biomed Opt 15:067006, 2010

17. Marbacher S, Klinger E, Schwyzer L, Fischer I, Nevzati E, Diepers M, et al: Use of fluorescence to guide resection or biopsy of primary brain tumors and brain metastases. Neurosurg Focus 36(2):E10, 2014

18. McGirt MJ, Chaichana KL, Attenello FJ, Weingart JD, Than $\mathrm{K}$, Burger PC, et al: Extent of surgical resection is independently associated with survival in patients with hemispheric infiltrating low-grade gliomas. Neurosurgery 63:700-708, 2008

19. Millesi M, Kiesel B, Woehrer A, Hainfellner JA, Novak K, Martínez-Moreno M, et al: Analysis of 5-aminolevulinic acid-induced fluorescence in 55 different spinal tumors. Neurosurg Focus 36(2):E11, 2014

20. Montcel B, Mahieu-Williame L, Armoiry X, Meyronet D, Guyotat J: Two-peaked 5-ALA-induced PpIX fluorescence emission spectrum distinguishes glioblastomas from low grade gliomas and infiltrative component of glioblastomas. Biomed Opt Express 4:548-558, 2013

21. Nabavi A, Thurm H, Zountsas B, Pietsch T, Lanfermann H, Pichlmeier U, et al: Five-aminolevulinic acid for fluorescence-guided resection of recurrent malignant gliomas: a phase II study. Neurosurgery 65:1070-1077, 2009

22. Nakazato Y: [Revised WHO classification of brain tumours.] Brain Nerve 60:59-77, 2008 (Jpn)

23. Pichlmeier U, Bink A, Schackert G, Stummer W: Resection and survival in glioblastoma multiforme: an RTOG recursive partitioning analysis of ALA study patients. Neuro Oncol 10:1025-1034, 2008

24. Pogue BW, Gibbs-Strauss S, Valdés PA, Samkoe K, Roberts DW, Paulsen KD: Review of neurosurgical fluorescence imaging methodologies. IEEE J Sel Top Quantum Electron 16:493-505, 2010

25. Richards-Kortum R, Sevick-Muraca E: Quantitative optical spectroscopy for tissue diagnosis. Annu Rev Phys Chem 47:555-606, 1996

26. Roberts DW, Valdés PA, Harris BT, Fontaine KM, Hartov A, Fan X, et al: Coregistered fluorescence-enhanced tumor resection of malignant glioma: relationships between $\delta$ aminolevulinic acid-induced protoporphyrin IX fluorescence, magnetic resonance imaging enhancement, and neuropathological parameters. Clinical article. J Neurosurg 114:595603, 2011

27. Roberts DW, Valdés PA, Harris BT, Hartov A, Fan X, Ji S, et al: Adjuncts for maximizing resection: 5-aminolevuinic acid. Clin Neurosurg 59:75-78, 2012

28. Roberts DW, Valdés PA, Harris BT, Hartov A, Fan X, Ji S, et al: Glioblastoma multiforme treatment with clinical trials for surgical resection (aminolevulinic acid). Neurosurg Clin $\mathbf{N}$ Am 23:371-377, 2012

29. Ruge JR, Liu J: Use of 5-aminolevulinic acid for visualization and resection of a benign pediatric brain tumor. J Neurosurg Pediatr 4:484-486, 2009

30. Sanai N, Snyder LA, Honea NJ, Coons SW, Eschbacher JM, Smith KA, et al: Intraoperative confocal microscopy in the visualization of 5-aminolevulinic acid fluorescence in lowgrade gliomas. J Neurosurg 115:740-748, 2011

31. Schomas DA, Laack NN, Rao RD, Meyer FB, Shaw EG, O'Neill BP, et al: Intracranial low-grade gliomas in adults: 30-year experience with long-term follow-up at Mayo Clinic. Neuro Oncol 11:437-445, 2009

32. Shapiro DE: The interpretation of diagnostic tests. Stat Methods Med Res 8:113-134, 1999

33. Smith JS, Chang EF, Lamborn KR, Chang SM, Prados MD, Cha S, et al: Role of extent of resection in the long-term outcome of low-grade hemispheric gliomas. J Clin Oncol 26:1338-1345, 2008

34. Stockhammer F, Misch M, Horn P, Koch A, Fonyuy N, Plotkin M: Association of F18-fluoro-ethyl-tyrosin uptake and 5-aminolevulinic acid-induced fluorescence in gliomas. Acta Neurochir (Wien) 151:1377-1383, 2009

35. Stummer W, Novotny A, Stepp H, Goetz C, Bise K, Reulen HJ: Fluorescence-guided resection of glioblastoma multiforme by using 5-aminolevulinic acid-induced porphyrins: a prospective study in 52 consecutive patients. J Neurosurg 93:1003-1013, 2000

36. Stummer W, Pichlmeier U, Meinel T, Wiestler OD, Zanella F, Reulen HJ: Fluorescence-guided surgery with 5-aminolevulinic acid for resection of malignant glioma: a randomised controlled multicentre phase III trial. Lancet Oncol 7:392401, 2006

37. Stummer W, Reulen HJ, Meinel T, Pichlmeier U, Schumacher W, Tonn JC, et al: Extent of resection and survival in glioblastoma multiforme: identification of and adjustment for bias. Neurosurgery 62:564-576, 2008

38. Stummer W, Stepp H, Möller G, Ehrhardt A, Leonhard M, Reulen HJ: Technical principles for protoporphyrin-IX-fluorescence guided microsurgical resection of malignant glioma tissue. Acta Neurochir (Wien) 140:995-1000, 1998

39. Stummer W, Tonn JC, Goetz C, Ullrich W, Stepp H, Bink A, et al: 5-ALA-derived tumor fluorescence: the diagnostic accuracy of visible fluorescence qualities as corroborated by spectrometry and histology and post-operative imaging. Neurosurgery 74:310-319, 2013

40. Stummer W, Tonn JC, Mehdorn HM, Nestler U, Franz $\mathrm{K}$, Goetz C, et al: Counterbalancing risks and gains from extended resections in malignant glioma surgery: a supplemental analysis from the randomized 5-aminolevulinic acid glioma resection study. J Neurosurg 114:613-623, 2011

41. Utsuki S, Oka H, Sato S, Suzuki S, Shimizu S, Tanaka S, et al: Possibility of using laser spectroscopy for the intraoperative detection of nonfluorescing brain tumors and the boundaries of brain tumor infiltrates. Technical note. J Neurosurg 104:618-620, 2006

42. Valdés PA, Bekelis K, Harris BT, Wilson BC, Leblond F, Kim A, et al: 5-Aminolevulinic acid-induced protoporphyrin IX fluorescence in meningioma: qualitative and quantitative measurements in vivo. Neurosurgery 10 (Suppl 1):74-83, 2014 
43. Valdés PA, Fan X, Ji S, Harris BT, Paulsen KD, Roberts DW: Estimation of brain deformation for volumetric image updating in protoporphyrin IX fluorescence-guided resection. Stereotact Funct Neurosurg 88:1-10, 2010

44. Valdés PA, Leblond F, Jacobs VL, Paulsen KD, Roberts DW, In vivo fluorescence detection in surgery: A review of principles, methods, and applications. Curr Med Imaging Rev 8:211-232, 2012

45. Valdés PA, Jacobs VL, Wilson BC, Leblond F, Roberts DW, Paulsen KD: System and methods for wide-field quantitative fluorescence imaging during neurosurgery. Opt Lett 38:2786-2788, 2013

46. Valdés PA, Kim A, Brantsch M, Niu C, Moses ZB, Tosteson TD, et al: $\delta$-aminolevulinic acid-induced protoporphyrin IX concentration correlates with histopathologic markers of malignancy in human gliomas: the need for quantitative fluorescence-guided resection to identify regions of increasing malignancy. Neuro Oncol 13:846-856, 2011

47. Valdés PA, Kim A, Leblond F, Conde OM, Harris BT, Paulsen KD, et al: Combined fluorescence and reflectance spectroscopy for in vivo quantification of cancer biomarkers in low- and high-grade glioma surgery. J Biomed Opt 16:116007, 2011

48. Valdés PA, Leblond F, Jacobs VL, Wilson BC, Paulsen KD, Roberts DW: Quantitative, spectrally-resolved intraoperative fluorescence imaging. Sci Rep 2:798, 2012

49. Valdés PA, Leblond F, Kim A, Harris BT, Wilson BC, Fan $X$, et al: Quantitative fluorescence in intracranial tumor: implications for ALA-induced PpIX as an intraoperative biomarker. J Neurosurg 115:11-17, 2011
50. Valdés PA, Leblond F, Kim A, Wilson BC, Paulsen KD, Roberts DW: A spectrally constrained dual-band normalization technique for protoporphyrin IX quantification in fluorescence-guided surgery. Opt Lett 37:1817-1819, 2012

51. Weissleder R, Pittet MJ: Imaging in the era of molecular oncology. Nature 452:580-589, 2008

52. Widhalm G, Wolfsberger S, Minchev G, Woehrer A, Krssak M, Czech T, et al: 5-aminolevulinic acid is a promising marker for detection of anaplastic foci in diffusely infiltrating gliomas with nonsignificant contrast enhancement. Cancer 116:1545-1552, 2010

\section{Author Contributions}

Conception and design: Valdés, Wilson, Paulsen, Roberts. Acquisition of data: Valdés, Harris, Roberts. Analysis and interpretation of data: Valdés, Jacobs, Paulsen, Roberts. Drafting the article: Valdés, Jacobs. Critically revising the article: all authors. Reviewed submitted version of manuscript: all authors. Approved the final version of the manuscript on behalf of all authors: Valdés. Statistical analysis: Valdés, Jacobs. Administrative/technical/material support: Wilson, Leblond, Paulsen, Roberts. Study supervision: Valdés, Paulsen, Roberts.

\section{Correspondence}

Pablo A. Valdés, Department of Neurosurgery, Brigham and Women's Hospital, Harvard Medical School, 75 Francis St., AB-136, Boston, MA 02115. email: pvaldesquevedo@partners. org. 